\title{
Incidence and multiplex PCR based detection of trichothecene chemotypes of Fusarium culmorum isolates collected from freshly harvested Maize kernels in Southern India
}

\author{
M. Venkataramana, P. Shilpa, K. Balakrishna, H.S. Murali, H.V. Batra \\ Defence Food Research Laboratory, Microbiology Devision, Sidartha Nagar, Mysore, Karnataka, India.
}

Submitted: October 29, 2011; Approved: July 23, 2012

\begin{abstract}
Hundred Fusarium culmorum strains, isolated from freshly harvested maize grain samples from Southern parts of India, were incubated in czapek-dox medium and analyzed for trichothecene (DON/NIV) production. The mPCR assay was standardized targeting trichothecene metabolic pathway genes viz., Tri6, Tri7, Tril3 for detection of trichothecene (DON/NIV) chemotypes and $r D N A$ gene for specific detection of $F$. culmorum species. Primers for targeted genes were designed and used to predict whether these isolates could produce deoxynivalenol/nivalenol, 94 isolates were able to produce DON/NIV by mPCR assay. Chemical analysis of DON/NIV was carried out for mPCR positive isolates by high performance-thin layer chromatography (HPTLC). To check the practical usefulness of developed mPCR assay, 150 field samples of maize were evaluated and results were compared with conventional HPTLC method. Out of 150 samples, $34 \%$ samples stayed as a positive for NIV contamination whereas $44 \%$ were found to have deoxynivalenol contamination. Moreover, mPCR results are equivocally matched with the HPTLC chemical analysis for field samples. Chemotyping of $F$. culmorum isolates were reported for the first time from India, and highlights the important potential of $F$. culmorum to contaminate maize with DON/NIV.
\end{abstract}

Key words: deoxynivalenol, nivalenol, multiplex PCR assay, HPTLC.

\section{Introduction}

The genus Fusarium is a common fungal contaminant of many economically important field crops and food products, which causes a major contamination in human and animal nutrition. Fusarium sp. infects many important food grains, such as maize, wheat, barley, rice, millet, oat and rye, and produce highly toxic secondary metabolites known as mycotoxins. The major classes of Fusarium mycotoxins are trichothecenes and fumonisins. According to the type of trichothecene production, some Fusarium species, like $F$. culmorum and other species have been divided into two chemotypes: (i) the nivalenol chemotype, which includes isolates producing nivalenol and fusarenone $\mathrm{X}$, and (ii) the deoxynivalenol chemotype, which includes isolates producing deoxynivalenol and acetyldeoxynivalenol (Langseth et al., 1999; Muthomi et al., 2000). Trichothecenes can cause wide range of acute and chronic effects in humans and animals through ingestion of food and feed prepared from cereal crops contaminated with the toxins (Mello et al., 1999). The effects include skin inflammation, digestive disorders, trachycardia, oedema and haemorrhages in several internal organs, haemolytic disorders, impairment of immune disorders and nervous disorders (IARC, 1993).

Contamination of maize grains with trichothecenes is a common problem throughout the World, especially in temperate regions like India (Janardhana et al., 1999; Venkataramana et al., 2011). In Southern India, maize is grown under different ecological conditions and is harvested with fairly high trichothecene contaminations (Janardhana et al., 1999). Recent reports indicate that maize is prone to fungal infection during the pre and post harvest period (Bilgrami et al., 1980; Sinha, 1990). Vasanthkumar (Vasanthkumar, 1986) studied the infection of maize by field and storage 
moulds during pre and post harvest practices in relation to seed-borne fungal diseases of maize. Thimmappaiah et al. (1987) reported the natural occurrence of Fusarium toxins such as T-2 toxin, deacetoxyscirpenol and zearalenone in peanut, sorghum and maize from Mysore districts of Southern India. Pre-harvest succession of fungi in ripening maize grains has been reported by Banerjee et al. (Beyer et al., 2005).

The usual methods for chemotyping of Fusarium isolates are high performance liquid chromatography (HPLC) or gas chromatography/mass spectroscopy (GS/MS) analysis of extracts from substrates such as maize artificially inoculated with Fusarium (Sugiura et al., 1990; Muthomi et al., 2000). These methods are commonly applied due to their high sensitivity and specificity. However, these methods are rather labour-intensive and require sophisticated instrumentation and skilled operators. Recent studies are focusing genotypic identification of toxigenic fungi through molecular methods. DNA based methods that rely on the amplification of the genes involved in the biosynthesis of trichothecenes also are available. Specific PCR primers have been developed to the specific genes (Tri5, Tri6, Tri7 and Tri13) which are involved in trichothecene metabolism (Venkataramana et al., 2011; Lee et al., 2001). Some of the genes have been sequenced and found to be functional in NIV-producing isolates and nonfunctional in DON-producing isolates (Lee et al., 2002, 2001; Chandler et al., 2003).

The distribution of each chemotype/genotype varies by geographic region. Thus, strains of $F$. culmorum with DON and NIV chemotype/ genotype are known from several countries, including UK (Jennings et al., 2004), Germany (Muthomi et al., 2000), the Netherlands and Norway (Langseth et al., 1999), Italy (Gang et al., 1998), France (Bakan et al., 2001), USA (Mirocha et al., 1994), Canada (Abramson et al., 2001). However in India, we are first time reporting incidence of trichothecene chemotypes of $F$. culmorum on maize kernels by multiplex PCR method.

In the present study a novel mPCR method was developed for detection of trichothecene chemotypes of $F$. culmorum. Developed method was successfully evaluated in terms of sensitivity, specificity and reliability on to artificially contaminated samples as well as contaminated field samples of maize.

\section{Materials and Methods}

\section{Sampling area}

A total of 150 freshly harvested maize kernel samples were randomly collected from Karnataka and Andhra Pradesh, two districts from each state viz., Kusalnagara and Mysore districts of Karnataka; Srikakulam and Vizianagaram districts of Andhra Pradesh, India. Collected samples were stored at $4{ }^{\circ} \mathrm{C}$ for further analysis of mycoflora and toxin detection.
Isolation and identification of moulds from infected maize grains

\section{Isolation of mycoflora}

$F$. culmorum and other fungal genera were isolated from the infected maize grains using Potato Dextrose Agar (PDA) media. The morphological identification of Fusarium species were followed by the previous reports of Nelson et al. (1983). The pure cultures of Fusarium was maintained on SNA plates and stored at $4{ }^{\circ} \mathrm{C}$ for analysis of toxins.

\section{DNA extraction}

DNA was extracted from pure cultures of Fusarium sp., using commercially available DNA extraction kits (QUIAZEN, Gambh).

\section{Isolation of DNA from contaminated food grains}

Twenty grams of contaminated food sample was ground in coffee grinder for $90 \mathrm{~s}$ and then $0.2 \mathrm{~g}$ ground grain was mixed in $1 \mathrm{~mL}$ lysis buffer $(100 \mathrm{mM}$ Tris- $\mathrm{HCl}$, $50 \mathrm{mM}$ EDTA, $150 \mathrm{mM} \mathrm{NaCl}$ and 1\% SDS) and homogenized by gentle mixing and kept it for water bath at $60^{\circ} \mathrm{C}$ for $10 \mathrm{~min}$. Samples were centrifuged at $12000 \mathrm{x} \mathrm{g}$ for 5 min and $500 \mu \mathrm{L}$ of supernatant was mixed with $150 \mu \mathrm{L}$ of $5 \mathrm{M}$ potassium acetate and incubated on ice for $10 \mathrm{~min}$. After centrifugation a $400 \mu \mathrm{L}$ of supernatant was mixed with $300 \mu \mathrm{L}$ of ice cold isopropanol to precipitate the DNA, the resulting pellet was washed with $70 \%$ ethanol, dried under air and dissolved in $50 \mu \mathrm{L}$ of Tris-EDTA (pH 8.0).

\section{Development of primers and PCR analysis}

\section{Designing of primers}

DNA sequences were analysed and aligned by Clustal method. Primers were designed using the aligned gene bank database sequences viz., Tri6, Tri7, Tri13 and rDNA genes for the specific detection of nivalenol and deoxynivalenol producing F. culmorum. Total of four primer pairs were designed using Gene runner software (http://www.generunner.com). Primer sequences are listed in Table 1. Before standardizing mPCR protocol, all designed primers were evaluated on to array of fungal species to check the specificity and sensitivity.

\section{Multiplex PCR assay}

Multiplex PCR was carried out for DON and NIV producing $F$. culmorum in an Eppendorf master cycler gradient (Hamburg, Germany) with a reaction volume of $30 \mu \mathrm{L}$. The amplification mixture consisted of template DNA (1.0 $\mu \mathrm{L}), \mathrm{MgCl}_{2}(2.0 \mathrm{mM}), 1 \mathrm{X}$ PCR buffer (Sigma), dNTP mix (200 $\mu$ M, MBI, Fermentas), Taq polymerase (1 unit, Sigma) and primer pairs specific to the targeted genes Tri6, Tri7,Tri13 and $r D N A$ were added at a concentration of $100 \mathrm{nM}, 150 \mathrm{nM}, 200 \mathrm{nM}$ and $50 \mathrm{nM}$, respectively. The PCR cycling conditions were carried out with an initial de- 
Table 1 - Primers used in this study.

\begin{tabular}{|c|c|c|c|c|c|}
\hline Primer & Sequence $\left(5^{\prime}-3^{\prime}\right)$ & Product size & Targeted gene & Accession No & Annealing temperature \\
\hline Fcu F & GATGCCAGACCAAGACGAAG & $302 \mathrm{bp}$ & rDNA 1-302 & AY880844.1 & $58{ }^{\circ} \mathrm{C}$ \\
\hline Fcu R & GGTTAGAATCATGCCGACC & & & & \\
\hline $\operatorname{tri} 6 \mathrm{~F}$ & GATCTAAACGACTATGAATCACC & $541 \mathrm{bp}$ & TRI6 99-640 & AY134893.1 & $58^{\circ} \mathrm{C}$ \\
\hline tri6 R & GCCTATAGTGATCTCGCATGT & & & & \\
\hline tri7F & ATAGGTACCGGATCGCAGG & $794 \mathrm{bp}$ & TRI7 1-794 & FJ152469.1 & $58^{\circ} \mathrm{C}$ \\
\hline tri7R & CCGAAAGCCTCTAATAGTGT & & & & \\
\hline $\operatorname{tri13~F}$ & GTTGCAGTTCGCTTGATTTCG & $1000 \mathrm{bp}$ & TRII3 60-1060 & FJ152465.1 & $58^{\circ} \mathrm{C}$ \\
\hline tri13 R & GTTGCAGTTCGCTTGATTCAG & & & & \\
\hline
\end{tabular}

naturation at $94{ }^{\circ} \mathrm{C}$ for $4 \mathrm{~min}$, followed by 30 cycles of $94^{\circ} \mathrm{C}$ for $1 \mathrm{~min}, 58^{\circ} \mathrm{C}$ for $1 \mathrm{~min}$ and $72^{\circ} \mathrm{C}$ for $1.5 \mathrm{~min}$, with a final extension of $72{ }^{\circ} \mathrm{C}$ for $8 \mathrm{~min}$.

\section{Specificity and sensitivity of $\mathrm{MPCR}$ on artificially contaminated maize grains}

The specificity of the mPCR primers was determined against different organisms shown in (Table 2). Sterile maize grains $(5 \mathrm{~g})$ were experimentally spiked with $F$. culmorum spore suspensions at different concentrations $\left(1 \times 10^{5}, 1 \times 10^{4}, 1 \times 10^{3}\right.$ and $\left.1 \times 10^{2} \mathrm{cfu} \mathrm{g}^{-1}\right)$. Negative controls were kept without inoculation of spores. All the samples were enriched for two days, further DNA was isolated and analysed by mPCR assay.

\section{Application of mPCR on field samples}

\section{Analysis of field samples}

Maize samples were collected from various fields of Andhra Pradesh and Karnataka, India and processed as described earlier and all of these samples were subjected to mPCR assay and toxins are analyzed by HPTLC.

\section{Chemical analysis of DON and NIV}

\section{Extraction and cleanup}

Briefly, $50 \mathrm{~g}$ of the well ground sample was extracted with $250 \mathrm{~mL}$ of acetonitrile-water (60:40, v/v) using high speed blending for $2 \mathrm{~min}$. The extract was filtered through Whatman No. 4 filter paper and an equal volume of ethyl acetate was added to the filtrate and separated the lower chloroform fraction and evaporated to dryness. Dried compound was diluted with PBS and passed through immunoaffinity columns (VICAM, USA) for clean-up. After washing with water, DON/NIV were eluted with methanol. These extracts further used for HPTLC analysis.

\section{HPTLC detection}

High performance thin layer chromatography (HPTLC) technique was used to detect the specific chemotypes of (DON /NIV) F. culmorum. Chromatography was carried out on $10 \times 10 \mathrm{~cm}$ precoated silica gel HPTLC plates (Merck). Test samples and standards were applied
Table 2 - Standard cultures used in this study.

\begin{tabular}{llc}
\hline SNO & Name & Source \\
\hline 1 & Fusarium culmorum ITCC146 & IMTECH \\
2 & Fusarium culmorum ITCC149 & ITCC \\
3 & Fusarium culmorum ITCC148 & ITCC \\
4 & Fusarium graminearum MTCC 1893 & MTCC \\
5 & Fusarium graminearum ITCC 1805 & ITCC \\
6 & Fusarium moniliforme ITCC 3362 & ITCC \\
7 & Fusarium moniliforme ATCC 14164 & IMTECH \\
8 & Fusarium oxysporum NCIM 1072 & NCIM \\
9 & Fusarium oxysporum IMTECH 2480 & IMTECH \\
10 & Fusarium solani ITCC3359 & IMTECH \\
\hline
\end{tabular}

*IMTECH- Institute of Microbial Technology; ITCC- Indian Type Culture Collection; ATCC-American Type Culture Collection; NCIM - National Centre for Industrially important Microorganisms.

with automatic TLC sampler (ATS III) from CAMAG (Muttenz, Switzerland), with a $50 \mathrm{~mm}$ run length using: chloroform + methanol + water $(9+1+0.2, \mathrm{v} / \mathrm{v} / \mathrm{v}$. $)$ as mobile phase. Fluorescence detection was carried out by postchromatographic derivatization with $10 \%$ aluminium chloride (Sigma) in methanol-water mixture. The plate was immersed in the derivatization solution using a dipping device III (CAMAG) and heated for $20 \mathrm{~min}$ at $110{ }^{\circ} \mathrm{C}$. The plate was then scanned at $366 />400 \mathrm{~nm}$ with a densitometer TLC Scanner 3 (CAMAG) using a slit dimension of $5.0 \mathrm{x}$ $0.5 \mathrm{~mm}$ and scanning speed of $40 \mathrm{~mm} \mathrm{~s}^{-1}$ (18). DON and NIV standards (Sigma) at a concentration of $0.1 \mathrm{mg} / \mathrm{mL}$ in methanol: water $(1: 1)$ was used as positive controls for HPTLC detection.

\section{Results}

Incidence of mycotoxigenic Fusarium culmorum and other fungi

A total of 150 Fusarium isolates were identified from the maize samples of the present study. Out of 150 fungal isolates, 100 isolates were identified with $F$. culmorum morphologically (45 isolates from Karnataka and 55 iso- 
lates from Andhra Pradesh) and remaining 50 isolates from other species including $F$. sporotrichioides, $F$. verticillioides and $F$. proliferatum (Table 3 ).

\section{Multiplex PCR assay application and chemical analysis of pure cultures of fungi}

Primer concentrations (100 nM of Tri6, $150 \mathrm{nM}$ of Tri7, $200 \mathrm{nM}$ of Tri13 and $50 \mathrm{nM}$ of rDNA) and annealing temperature $\left(58^{\circ} \mathrm{C}\right)$ were standardized to get a uniform amplification of all the genes targeted for mPCR assay (Figure 1). Out of 150 Fusarium isolates, 100 were showed positive signal for $r D N A$ gene specific to $F$. culmorum (94 toxigenic to DON/NIV and remaining were non toxigenic by $\mathrm{mPCR}$ ). However, 54 and 34 strains of them were positive for DON and NIV respectively, and rest of the 7 strains were stayed as negative for the chemical analysis by HPTLC.

\section{Contamination studies}

The detection limit for deoxynivalinol and nivalenol producing $F$. culmorum strains from spiked samples by mPCR was $1 \times 10^{3} \mathrm{cfu} \mathrm{g}^{-1}$ maize grains. Samples tested with initial fungal load of $1 \times 10^{3} \mathrm{cfu} \mathrm{g}^{-1}$ and above concentrations following $48 \mathrm{~h}$ enrichment at $30{ }^{\circ} \mathrm{C}$ were positive for both toxins.

\section{MPCR and chemical analysis of field samples}

Out of 150 maize samples collected for mPCR studies, $78 \%$ samples were showed positive for toxigenic Fusarium species. However, only $34 \%$ of the total analysed samples were positive for NIV and $44 \%$ positive for DON chemotypes. Toxin analysis by HPTLC providing equivocal results with mPCR for both the groups of toxins.

\section{Discussion}

It would be more meaningful if analytical systems are made available for low cost, simple to use qualitative and

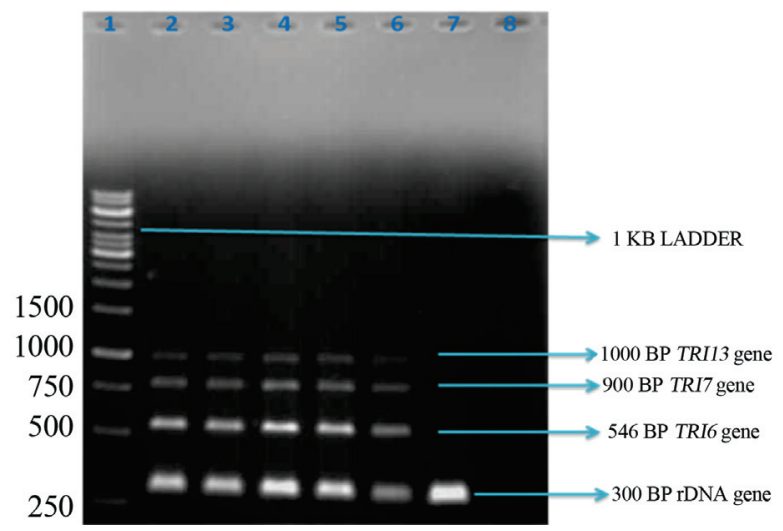

Figure 1 - Multiplex PCR photograph for DON and NIV producing F.culmorum Lane M: 1 kb DNA Ladder (MBI Fermentas, Mumbai, India); lanes 1 and 2: F. culmorum standard cultures; lanes 3, 4 and 5: F. culmorum isolates; lane 6 non toxigenic $F$. culmorum isolate; lane7: negative control. for quantitative assessments of the mycotoxigenic fungi and mycotoxins present in the different food matrices. Conventional methods for the detection of Fusarium based on sporodochia with abundant macroconidia on the chaff surface is time consuming and laborious, however, PCR assays have proven to be very useful and sensitive where sporodochia are absent or in poorly developed state (Nicholson et al., 1998). Multiplex PCR assays have been applied for the detection of air samples and for diseased plant, animal and human tissues for the presence of bacteria, parasites, viruses and fungi (Yenny et al., 2009; Mohd et al., 2010). In this study, we attempted a mPCR assay with an objective to obtain simultaneous detection of trichothecene chemotypes of $F$. culmorum spp. that are commonly associated with Fusarium disease.

A total of 150 Fusarium isolates originated from Andhra Pradesh and Karnataka, India were assayed by $\mathrm{mPCR} / \mathrm{HPTLC}$ for their mycotoxin chemotypes. Results were showed that 100 strains have the $r D N A$ gene specific to $F$. culmorum. Additionally mPCR amplification of Tri6, Tri7 and Tri13 alleles suggests that $94 \%$ of the $F$. culmorum isolates are able to produce DON/NIV. Some other researchers observed that, the same NIV and DON accumulation by F. culmorum in wheat grains (Kammoun et al., 2009; Lobna et al., 2010). However, to our knowledge in India, we are reporting first time DON/NIV chemotypes in maize kernels. In the present study, DON chemotypes were more aggressive when compared to NIV chemotypes of $F$. culmorum. The higher incidence of DON chemotypes may be due to intra specific variation of gene clusters of $F$. culmorum strains (Bakan et al., 2001). The findings of Jennings et al. (2004) were confirmed our results, that DON chemotypes dominance in $F$. culmorum strains. Whereas, Lauren et al. (1992) and Lee et al. (2002) reported contradictory results that NIV dominants in $F$. culmorum.

The four DNA amplicons scored (Figure 1) were serve as a diagnostic tool for the early detection of trichothecene chemotypes of $F$. culmorum. The $300 \mathrm{bp}$ amplicon is signifies the $r D N A$ gene specific to $F$. culmorum, $546 \mathrm{bp}$ region of Tri6 gene is specific to all trichothecene producing Fusarium species (both type A and type B) whereas, 900 bp Tri7 gene region specific to NIV chemotype and 1000 Bp region of Tril3 gene is specific to DON chemotypes of F. culmorum was used in this study.

Results of the molecular assays (mPCR) were confirmed by chemical analysis by HPTLC. Thus HPTLC conducted on $94 \mathrm{mPCR}$ positive $F$. culmorum isolates revealed that 54 isolates were positive for DON and 33 were positive for NIV toxin, whereas, 7 strains were negative for chemical analysis. The variation in MPCR and HPTLC analysis is not unexpected since Quarta et al. (2005) and Ramana et al., (2011) compared the molecular analysis with chemical analysis for toxigenic Fusarium species and made the similar kind of findings. Thus while a positive trichothecene 
genotype indicates the potential for trichothecene biosynthesis, only a test for the toxin itself can be used to determine if and how much toxin a strain has produced. In vitro, DON/NIV may be produced by utilizing very different culture conditions such as whole grain, solid substrate fermentation, or liquid cultures using a defined minimal medium. Our results corroborate that growth conditions greatly influence the amount of mycotoxin produced. trichothecene biosynthesis may be regulated by temperature (Ramirez et al., 2006), relative humidity (Beyer et al., 2005), and substrate composition (ONeill et al., 1993). Results lead to the conclusion that in vitro assays could not appropriate to predict production of DON in the field as suggested by Gang et al. (1998). The physiology of plant-hosts and pathogenesis of the strain itself may further influence mycotoxin accumulation under field conditions. However, in the case of field samples mPCR results are equivocally matched with the chemical analysis. So, the newly developed mPCR assay is an alternative for the time consuming and laborious conventional culture methods for early assessment of trichothecene chemotypes of $F$. culmorum from field samples. The present research has demonstrated that, the occurrence of F. culmorum in Southern India (Andhra Pradesh and Karnataka) is dominant; it may due to cool climatic conditions and high moisture and rainfalls. Global variation in DON/NIV production by isolates of F. culmorum and distribution of these isolates geographically and by host are important in Plant pathology and food safety and security.

\section{Conclusion}

High levels of toxigenic $F$. culmorum incidence in maize samples demonstrates the need for better surveillance and monitoring by policy makers or food toxicologists to reduce the exposure of human and animal life to toxic compounds produced by fungi.

\section{Acknowledgments}

Authors are thankful to the director DFRL, Mysore, for his providing necessary facilities to carry out the work.

\section{References}

Abramson D, Clear RM, Gaba D, Smith D, Patrick SK, Saydak D (2001) Trichothecene and moniliformin production by Fusarium isolates from western Canadian wheat. J Food Prote 64:1220-1225.

Bakan B, Pinson L, Cahagnier B, Melcion D, Sémon E, RichardMolard D (2001) Toxigenic potential of Fusarium culmorum strains isolated from French wheat. Food Addi Contami 18:998-1003.

Banerjee A, Shetty HS, Majumdar SK (1988) Succession of mycoflora in ripening maize grain. Indian Phytopathology 41:562-566.

Beyer M, Verreet JA, Ragab WSM (2005) Effect of relative humidity on germination of ascospores and macro conidia of
Gibberella zeae and deoxynivalenol production. Int J Food Microbiol 98:233-240.

Bilgrami KS, Prasad T, Misra RS, Sinha KK (1980) Survey and study of mycotoxin producing fungi associated with the grains in standing maize crops. Final Technical Report. ICAR project, Bhagalpur University, India.

Chandler EA, Simpson DR, Thomsett MA, Nicholson P (2003) Development of PCR assays to Tri7 and Tril 3 trichothecene biosynthetic genes, and characterisation of chemotypes of Fusarium graminearum, Fusarium culmorum and Fusarium cerealis. Phys Mol Plant Pathol 62:355-367.

Chu FS (1996) Recent studies on immunoassays for mycotoxins. In: Beier RC, Stanker LH (eds) Immunoassays for Residue Analysis: Food Safety. ACS Symposium Series 621. American Chemical Society, Washington DC, pp 294-313.

Gang G, Miedaner T, Schuhmacher U, Schollenberger M, Geiger HH (1998) Deoxynivalenol and nivalenol production by Fusarium culmorum isolates differing in aggressiveness toward winter rye. Phytopathology 88:879-884.

IARC (1993) Some Naturally Occurring Substances: Food Items and Constituents, Heterocyclic Aromatic Amines and Mycotoxins, Volume 56. WHO, Lyon, 599 pp.

Janardhana GR, Raveesha KA, ShekarShetty H (1999) Mycotoxin contamination of maize grains grown in Karnataka (India). Food Chem Toxicol 37:863-868.

Jennings P, Coates ME, Turner JA, Chandler EA, Nicholson P (2004) Determination of deoxynivalenol and nivalenol chemotypes of Fusarium culmorum isolates from England and Wales by PCR assay. Plant Pathol 53:182-190.

Kammoun GL, Gargouri S, Hajlaoui MR, Marrakchi M (2009) Occurrence and disTribution of Microdochium and Fusarium species isolated from durum wheat in northern Tunisia and detection of mycotoxins in naturally infested grain. J Phytopathol 157:546-551.

Langseth W, Bernhoft A, Rundberget T, Kosiak B, Gareis M (1999) Mycotoxin production and cytotoxicity of Fusarium strains isolated from Norwegian cereals. Mycopathologia 144:103-113.

Lauren DR, Sayer ST, Dimenna ME (1992) Trichothecene production by Fusarium species isolated from grain and pasture throughout New Zealand. Mycopathologica 120:167-176.

Lee T, Han YK, Kim KH, Yun SH, Lee YW (2002) Tri13 and Tri7 determine deoxynivalenol and nivalenol producing chemotypes of Gibberella zeae. App Environ Microbiol 68:21482154.

Lee T, Oh DW, Kim HS, Lee J, Kim YH, Yun SH, Lee YW (2001) Identification of deoxynivalenol and nivalenol producing chemotypes of Gibberella zeae by using PCR. App Environ Microbiol 67:2966-2972.

Lobna GK, Samia G, Christian B, Florence R, Mohamed RH (2010) Trichothecene chemotypes of Fusarium culmorum infecting wheat in Tunisia. Int J Food Microbiol 140:84-89.

MarioV, Daniela C. (2006) Determination of Deoxynivalenol in wheat by validated GC/ECD method: Comparison with HPTLC/FLD. Electronic. J Food Plant Chem 1:16-20.

Mello JPFD, Placinta CM, MacDonald AMC (1999) Fusarium mycotoxins: A review of global implications for animal health, welfare and productivity. Anim Feed Sci Technol 80:183-205.

Mirocha CJ, Xie W, Xu Y, Wilcoxson RD, Woodward RP, Etebarian $\mathrm{RH}$, Behele G (1994) Production of trichothecene my- 
cotoxins by Fusarium graminearum and Fusarium culmorum or barley and wheat. Mycopathologia 128:19-23.

Mohd E, Elhassan N, Kwai LT (2010) Differentiation of Salmonella enterica based on PCR detection of selected somatic and flagellar antigens. Afr J Microb Res 4:871-876.

Muthomi JW, Schutze A, Dehne HW, Mutitu EW, Oerke EC (2000) Characterization of Fusarium culmorum isolates by mycotoxin production and aggressiveness to winter wheat. Z Pflanzenk Pflanzen 107:113-123.

Nelson PE, Toussoun TA, Marasa WFO (1983) Fusarium species. An Illustrated Manual for identification. Pennsylvania State University Press, University Park.

Nicholson P, Simpson DR, Weston G, Rezanoor HN, Lees AK, Parry DW, Joyce D (1998) Detection and quantification of Fusarium culmorum and Fusarium graminearum in cereals using PCR assays. Phy Mole P Pathol 53:17-37.

ONeill K, Damaglou AP, Patterson MF (1993) Toxin production by Fusarium culmorum IMI 309344 and F. graminearum NRRL 5883 on grain substrates. J App Bacteriol 74:625628 .

Quarta A, Mita G, Haidukowski M, Santino A, Mule G, Visconti A (2005) Assessment of trichothecene chemotypes of Fusarium culmorum occurring in Europe. Food Addi Contam 22:309-315.

Ramirez ML, Chulze S, Magan N (2006) Temperature and water activity effects on growth and temporal deoxynivalenol pro- duction by two Argentinean strains of Fusarium graminearum on irradiated wheat grain. Int $\mathrm{J}$ Food Microbiol 106:291-296.

Sinha K (1990) Incidence of mycotoxins in maize grains in Bihar State (India). Food Addi Contam 7:55-61.

Sugiura Y, Watanabe Y, Tanaka T, Yamamoto S, Ueno Y (1990) Occurrence of Gibberella zeae strains that produce both nivalenol and deoxynivalenol. App Environ Microbiol 56:3047-3051.

Thimmappaiah N, Bhavanishankar P, Shantha T (1987) Natural occurrence of Fusarium toxins in peanut, sorghum and maize from Mysore (India). J Sci Food Agric 40:127-132.

Vasanthkumar. (1986) Studies on some seed-borne fungal diseases of maize in Karnataka. PhD Thesis, University of Mysore, India.

Venkata Ramana M, Balakrishna K, Murali HS, Batra HV (2011) Multiplex PCR-based strategy to detect contamination with mycotoxigenic Fusarium species in rice and fingermillet collected from southern India. J Sci Food Agric 91:16661673.

Yenny S, Maribeth A, Cousin B, Charles P, Woloshuk (2009) Multiplex real-time PCR for detection and quantification of mycotoxigenic Aspergillus, Penicillium and Fusarium. J Stor Pro Res 45:139-145.

All the content of the journal, except where otherwise noted, is licensed under a Creative Commons License CC BY-NC. 